\title{
Reescrituras del Silabario Hispanoamericano en la poesía chilena reciente*
}

\author{
Diego Zamora Estay ${ }^{* *}$
}

\begin{abstract}
Resumen
El siguiente artículo analiza la reescritura poética del Silabario Hispanoamericano, del profesor Adrián Dufflocq, a través de tres poetas chilenos: Rodrigo Ortega, Marcela Parra y Malú Urriola, quienes analizan las construcciones ideológicas que sostienen la cultura hegemónica de la República chilena y la relación entre pedagogía y poesía como espacio de construcción histórico-política del sujeto infante. En estos poetas, la reescritura es juego, un recurso literario que busca transformar la cultura, modificando los paradigmas históricos de la niñez chilena que han sido establecidos, sobre todo, por la institución escolar y estatal del país.
\end{abstract}

Palabras clave: poesía chilena, reescritura, silabario, pedagogía, infancia.

\section{Rewriting of the Silabario Hispanoamericano in recent Chilean poetry}

\begin{abstract}
This article analizes the poetic rewriting about the Silabario Hispanoamericano of the teacher Adrián Dufflocq, through three chilean poets: Rodrigo Ortega, Marcela Parra and Malú Urriola, who analize the ideological construction that holds on the hegemonic culture of chilean Republic and the relation between pedagogy and poetry, like an space of historic and political construction, modifying historic paradigms of the Chilean childhood that have been stablished, especially, by school and state institution of the country.
\end{abstract}

Key words: Chilean poetry, rewriting, syllabary, pedagogy, childhood.

Recibido: 10/09/2018

Aceptado: 24/02/2019

Ese artículo forma parte del proyecto FONDECYT 11170009, "Reescribir o el comienzo de la escritura: poéticas del campo cultural chileno-peruano (1943-2014)”, cuya investigadora responsable es la profesora Biviana Hernández.

** Chileno. Estudiante de Pedagogía en Lengua Castellana de la Universidad Academia de Humanismo Cristiano, Santiago, Chile. diegoandres.zamora@gmail.com 


\section{La enseñanza de la lengua como práctica republicana: relecturas de nuestro aprendizaje}

"Y no es que el pueblo sea analfabeto, sino que quiere decir cosas que nosotros ya no decimos"

Rodolfo Kusch

Los silabarios son textos educativos para el aprendizaje de la lectura y escritura utilizados en la educación primaria. Su uso de forma masiva en Chile lo podemos ubicar en la segunda mitad del siglo XIX, época en que se desarrolla el proceso de nacionalización o chilenización de la sociedad a partir de mecanismos culturales, como la escuela y la prensa, que buscan formar una conciencia ciudadana con el Estado y la elite como principales gestores de esta construcción (Subercaseaux, 2007).

En 1842 ${ }^{1}$, el entonces Director de la Escuela Normal de Preceptores, Domingo Faustino Sarmiento, publica el Análisis de las cartillas, silabarios y otros métodos de lectura conocidos y practicados en Chile, presentado al Ministro de Instrucción Pública Manuel Montt con el fin de mejorar los diferentes métodos de aprendizaje utilizados en la época, además de exaltar la importancia de la educación primaria que el intelectual argentino denomina como "la medida de la civilización de un pueblo" (7). Este texto no solo nos permite revisar las prácticas pedagógicas utilizadas en el aprendizaje de la lengua; también nos confirma que en este período el uso del silabario se entiende como un instrumento de carácter político.

En esa misma perspectiva se busca, a través de la educación primaria, la solución frente al debilitamiento del sentido nacional (Subercaseaux 2007) y el aumento de una población inadaptada a los sentidos morales que exigía la nueva nación, los que se consideraban problemas centrales para el gobierno de Chile a finales del siglo XIX y principios del XX. Como indican Salazar y Pinto en el quinto tomo de Historia contemporánea de Chile (2002), con la educación no se pretendía sacar a la ciudadanía de la pobreza, sino que aplicar un control a favor de la higiene y la normalización,

El año 1842 es de suma importancia para la historia cultural de Chile por la publicación del periódico Semanario de José Victorino Lastarria, en el cual tienen cita las ideas de la que sería conocida como Generación del 42, que reúne a escritores, políticos, educadores y a otros intelectuales de la época, como Andrés Bello, Antonio Varas, Eusebio Lillo, Francisco Bilbao, Vicente Pérez Rosales, entre otros. La Generación del 42 suscita un ambiente de crítica que da un impulso al país hacia el desarrollo intelectual, con clara preocupación por el progreso educacional de la nación. 
por lo que el apoyo de los gobiernos a la escolarización de los niños y niñas del país estaba destinado a "enseñarles nociones mínimas de lectura, escritura, doctrina cristiana y, sobre todo, normas de moral" (55). Dentro de este marco histórico, nos interesa tensionar la relación que el proyecto republicano mantiene con la lengua como medio principal de adaptación y acondicionamiento para el futuro ciudadano chileno.

El siguiente trabajo provoca esta tensión a partir del estudio del que es posiblemente el silabario más importante de nuestro país y de toda el habla hispana, el Silabario Hispanoamericano (1953) del profesor Adrián Dufflocq Galdames, con ilustraciones de Mario Silva Ossa (conocido por su seudónimo Coré) y publicado por primera vez el año 1945. Entendemos la importancia de este libro de acuerdo con tres ejes: 1) el aspecto espacial: desde sus primeros años logró estar presente en la mayoría de los países de habla hispana, siendo utilizado como método oficial del aprendizaje de la lengua en varios de ellos, incluyendo España; 2) el aspecto temporal: su uso ha estado vigente desde su publicación hasta la fecha, siendo considerado por padres y pedagogos para el aprendizaje de la lengua en la educación básica. Actualmente son varias las editoriales que reimprimen el mismo texto, con pocas modificaciones, además de mantener su presencia tanto en grandes cadenas de librerías como en el mercado pirata; y 3) el aspecto referencial: el contenido de este libro tiene antecedentes en otros de uso similar, como el Método de lectura gradual (1849) de Domingo Faustino Sarmiento y el Nuevo método para la enseñanza simultánea de la lectura i escritura (1884), conocido como "El ojo", del pedagogo y rector de la Universidad de Chile, Claudio Matte.

El proyecto de Dufflocq resulta sobresaliente en este tipo de textos, pues marca un antecedente de mejora técnica por su método fónicosensorial-objetivo-sintético ${ }^{2}$ que resuelve las problemáticas de las propuestas anteriores ${ }^{3}$, además de incluir las ilustraciones de Coré que

En el prólogo a la décima edición, el autor indica que su método "contiene una veintena de innovaciones" (5) y sería "único en su género" (5), aunque las palabras de Dufflocq desconocen la tradición en la cual está enmarcada su obra. Las características principales de este método son el aprendizaje "por medio de sonidos completos, base de nuestro lenguaje fonético" (6), y la asociación de imagen y texto pensado en el aprendizaje simultáneo de la lectura y la escritura. Estas dos líneas metodológicas están enmarcadas en dos principios básicos pedagógicos: "de lo conocido a lo nuevo y de lo simple a lo complejo" (5).

3 El trabajo de Dufflocq perfecciona los métodos de enseñanza de la lectura utilizados hasta la fecha. En este sentido, tanto el Análisis de las cartillas, silabarios y otros métodos de lectura conocidos y practicados en Chile (1842), como el Método de lectura gradual (1849) de Sarmiento, son dos antecedentes 
lograron un impacto cultural que, como veremos más adelante, siguen participando en la construcción de un imaginario social de la niñez.

Abordar, desde la poesía chilena reciente, un libro de estas características nos permite su actualización en contextos políticos y culturales actuales, como la situación del movimiento estudiantil que se presenta en las primeras dos décadas del siglo XXI desde la crisis de la educación chilena, teniendo el año 2006 como punto de inflexión ${ }^{4}$. La reescritura del libro de Dufflocq en poemarios publicados en estas décadas ha promovido nuevas lecturas en torno a la educación y su rol en el ámbito político-cultural, a partir de la toma de consciencia acerca de cómo han sedimentado este tipo de textos en nuestro presente y por qué siguen siendo de fundamental importancia para la política nacional.

Para realizar esta lectura, revisaremos la poesía de Rodrigo Ortega, Marcela Parra y Malú Urriola, considerando la influencia del Silabario Hispanoamericano en la manera en que entendemos el lenguaje y la relación entre imagen y palabra en la poesía chilena reciente, en un intento por actualizar los textos escolares utilizados en el país en sus años de formación republicana, y problematizar desde su reescritura los modos en que estos siguen siendo capitales para la educación formal en Chile.

Primero, abordaremos los textos de Ortega desde la reescritura de la infancia a partir de las imágenes del Silabario Hispanoamericano, utilizadas en su poemario Silabario (2012), que nos permiten comprender la construcción ideológica y político-cultural de la niñez y la presencia de las ilustraciones de Coré en este imaginario. Luego, analizaremos el poema "Silabario para maestros" del libro Silabario, Mancha (2008) de Marcela Parra, quien reescribe los ejercicios del libro de Dufflocq desde una vinculación explícita con La Nueva Novela (1977) de Juan Luis Martínez, para desencajar su carácter pedagógico y así poder

de gran importancia para la época, pues se piensan desde nuevos métodos traídos de Europa, además de identificarse con una línea laica, contraria a los métodos católicos que se empleaban generalmente, como las plegarias que eran utilizadas como textos de lectura. Entenderemos el Silabario Hispanoamericano desde esa propuesta pedagógica.

${ }_{4} \quad$ El movimiento estudiantil de los últimos años en Chile tiene sus representaciones en diferentes medios. En literatura, podemos mencionar la antología de varios autores, Poemas para negar la indiferencia y Quiltras de Arelis Uribe. En cine y televisión, la serie El reemplazante de Nicolás Acuña, el documental Ya no basta con marchar de Hernán Saavedra y la película La isla de los pingüinos de Guille Söhrens. 
abrir nuevas lecturas del mismo. La escritura de Parra nos sugiere una relación similar entre el uso de las imágenes en libros de aprendizaje y poemarios como Bracea $^{5}$ (2007) de Malú Urriola, quien utiliza la portada del Silabario Hispanoamericano en los fragmentos de "El padre de tres piernas", relacionando la experiencia de la infancia con el aprendizaje de la escritura, siendo este texto el último de nuestra indagación.

En los tres poemarios mencionados, la infancia se reescribe desde la relación crítica entre niñez y violencia, por un lado, y escritura e imagen, por otra; relaciones que nos permiten aproximarnos al texto de Dufflocq desde una mirada que proporciona nuevas perspectivas en torno a la enseñanza de la lengua en el contexto nacional; ya no solo desde los programas de alfabetización y culturización, sino también desde las violencias institucionales y simbólicas que sostienen estos discursos y que la poesía se ha encargado de visibilizar y cuestionar.

\section{Reescribir la infancia}

"Papá me enseña a amar la Patria. La Patria es la tierra donde nacimos."

María Alicia Domínguez

El libro Salibario de Rodrigo Ortega ${ }^{6}$, publicado por Editorial Moda \& Pueblo $^{7}$, fue lanzado el año 2012 como resultado final del taller Princesitas con capucha ${ }^{8}$ dirigido por Diego Ramírez en la Carnicería Punk, centro cultural que conduce hace diez años en la comuna de Santiago. La presentación del libro estuvo a cargo del poeta y dramaturgo Pablo Paredes, lo que nos permite situar las coordenadas de este poemario en la estética rebelde que han venido trabajando algunos autores de la llamada

\footnotetext{
5 El libro Bracea se inscribe en la trilogía de Malú Urriola que parte con Nada (2005) y tiene aún en proyección Vuela, "una trilogía que condensa una suerte de poética de su propio discurso" (Rojas 35). 6 Rodrigo Ortega (1993) es licenciado en Lengua y Literatura Hispánica, con mención en Literatura de la Universidad de Chile. Salibario es su primera publicación.

$7 \quad$ La Editorial Moda \& Pueblo publica los trabajos realizados por autores que participan en los talleres dirigidos por el escritor Diego Ramírez en la Carnicería Punk, centro cultural guiado por el mismo poeta que lleva más de diez años publicando poemarios de formato fanzine en tirajes limitados, relacionados con la noción de libro objeto.

El taller Princesitas con capucha, que da nombre a la colección, contó con la participación y publicación de otros ocho autores: Gabriela Contreras, Samuel Hidalgo, Carlos Leiton, Fanny León, Constanza Marchant, Gabriela Oleas, Arturo Pinto y Susana Rodríguez. Todos participantes de talleres anteriores en el mismo centro cultural.
} 
generación de los novísimos ${ }^{9}$. En los poemas de Ortega, encontramos ciertos cruces temáticos con libros como Frío en la noche latina (2005) de Paredes, donde la escritura de la infancia permite cuestionar la violencia de una patria en ruinas ${ }^{10}$.

Los poemas de Salibario articulan una infancia revisitada por una pareja de niños, que se presentan desde su sexualidad y salvajismo ante madres observadoras que mantienen una violencia latente, un espacio de crisis que tensiona la relación madre e hijo y, a la vez, constituye la unión entre los personajes infantiles con los adultos. Estos últimos parecen desesperados al no poder participar en los juegos eróticos de la infancia: "Ellas quieren tener sus cuerpos apretados y bonitos como los nuestros, las he visto con la boca abierta y llena de agua consolarse frente al televisor, las miré observar por horas a las moscas, he notado que lavan las sábanas a diario y que lloran fumando" (s/r).

Por otro lado, la figura del padre es una ausencia que cruza la narración, difuminándose en las alusiones a la patria, pero también confundiéndose con el sujeto amoroso. El lector se ve interpelado a preguntarse por la presencia de este padre ausente desde un principio, pues el autor da comienzo al poemario con la relación crítica entre padre e hijo por medio de la cita, en el epígrafe, de la Carta al padre de Franz Kafka:

En cualquier caso, éramos tan distintos, y en esta diferencia tan peligrosos el uno para el otro, que, si se hubiese podido calcular de antemano cómo se relacionarían el uno con el otro, yo, el

\footnotetext{
$9 \quad$ En palabras del poeta Héctor Hernández Montecinos, la novísima “fue un nombre que se le asignó a un conjunto de escrituras que aparecieron desde el año 2000, emparentadas por la amistad de sus autores y por la correspondencia en sus espacios inaugurales de circulación. Una de sus señales es que acerca la noción de joven poeta a lo que significa el inicio de la mayoría de edad, es decir, fue una instancia en que muchachos y muchachas de alrededor de dieciocho o diecinueve años comienzan a escribir sus proyectos personales con apuestas estéticas más bien cercanas a la experimentación, la radicalidad, el riesgo escritural. [...]. Las poéticas de Paula Ilabaca, Diego Ramírez, Pablo Paredes, Felipe Ruiz, Gladys González y algunas más son desde su momento mismo de escritura una interrupción y una problematización desde varios ángulos. No hay manifiestos, ni reuniones secretas, ni nada de eso, simplemente un grupo de amigos primeramente, luego una pandilla poética como dice Paredes y ya. Todos escribimos sumamente distintos, leemos cosas distintas, nos movemos en discursos y tensiones distintas y eso es uno de los valores agregados, su misma heterogeneidad nómade. Algunos han querido aglutinarnos, pero sin duda el corpus se escapa solo de esas categorizaciones. No es más que escritura honesta, sin miedo al error formal, y siendo el soporte de nuevas formas de rebeldías como el delirio y la ternura, entre otras" (Aplabaza 5).

10 Sobre esto, Biviana Hernández y Francisco Simón (2017) sostienen que cierta zona de la joven poesía chilena de los 2000 (Antonio Silva, Felipe Ruiz, Héctor Hernández, Gustavo Barrera, entre otros) ha elaborado voces infantiles que constituyen una "estrategia retórica para cuestionar las bases neoliberales de la democracia posdictatorial" (299).
} 
niño que se desarrolla lentamente, y tú el hombre ya acabado, se podría haber aceptado que tú fácilmente me aplastarías, que nada de mí podría permanecer. (s/r)

Con el uso de ilustraciones y extractos del Silabario Hispanoamericano, Ortega relaciona la obra de Dufflocq con esta infancia huérfana o "huacha", al decir del historiador Gabriel Salazar, sacando de contexto los fragmentos del silabario, resituándolos y resignificándolos, desde una perspectiva crítica y escéptica que, gracias a la operación de reescritura, logra tensionar el imaginario social e histórico de la niñez en tanto utopía humanista, formadora o emancipadora del niño "escolarizado" (Oltra y Puga, 2015); un niño que, como sujeto político-cultural, ha sido negado y silenciado históricamente al tratársele como un sujeto en formación que debe ser modelado, "una tarea a realizar a través de los grandes instrumentos modeladores de esos adultos" (Salazar 7). El intelectual argentino Domingo Faustino Sarmiento comprende esta formación como símil de la formación de los Estados americanos; es por ello que resalta la importancia de la educación primaria para civilizar al "bárbaro" y así poder transformarlo en ciudadano de la emergente República de Chile.

En la necesidad de superar esta fase de barbarie (la no-escolaridad del niño), Sarmiento piensa que es esencial la alianza entre el Estado, la Escuela y la Familia como gestores del progreso político y cultural: "ya es tiempo de que todos nos ocupemos sériamente [sic] de la mejora de la instrucción [sic] primaria, que tanto interés excita en todos los pueblos civilizados" (6). El autor hace un llamado a los ciudadanos para considerar como una tarea en común la instrucción de los niños y niñas de Chile, quejándose, a su vez, por el desinterés de los padres en la educación primaria que entendía como "la medida de la civilizacion [sic] de un pueblo" (7). Desde esta visión/misión educativa y formativa del niño, que habrá de devenir ciudadano, el Análisis de las cartillas, silabarios y otros métodos de lectura conocidos y practicados en Chile (1842) de Sarmiento no solo busca mejorar y homologar las técnicas e instrumentos de escolarización utilizados en la época; también es una propuesta política a favor de una alianza entre las instituciones mencionadas anteriormente.

Dufflocq también tiene considerada esta tríada institucional en el Silabario Hispanoamericano. En el prólogo a la décima edición, el autor hace referencia a los "padres que viven apartados de las escuelas y tienen que ser ellos los profesores de sus hijos" (5), padres en quienes 
ha pensado al momento de formular su método. Pero no solo la distancia con una escuela dificultó la escolarización y, sobre todo, la alfabetización, de los niños provenientes de familias obrero-campesinas, sino también las condiciones precarias que obligaban a muchos de ellos a trabajar para aportar en la economía familiar (Salazar, 2002). En este sentido, tanto Dufflocq como Sarmiento son intelectuales que no hacen mención de la condición socioeconómica de esas familias llamadas a participar en el proceso educativo de sus hijos; postulan, más bien, un modelo humanista basado en la visión idealista e idealizada de la institución familiar.

Pero, mientras en los relatos del Silabario Hispanoamericano las familias están constituidas por este ideal formativo del niño escolarizado, la familia de Salibario se relaciona con el abandono paternal, como queda plasmado en la siguiente imagen utilizada en el poema "Colmillo de leche" (s/r):
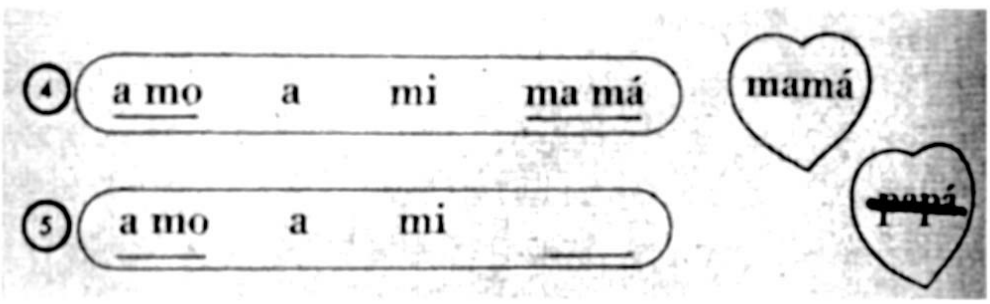

La tachadura sobre la palabra "papá" resiste a la filiación padre e hijo para constatar de forma violenta la ausencia del padre que, siguiendo la línea de Salazar, sería más acorde a la paternidad vivida en el país. La tachadura del padre es un gesto de rebeldía contra la tradición representada por la enseñanza de la lengua en perspectiva republicana, tal como sucede en Dufflocq, por lo que debemos entender esta relación entre lo paterno y el aprendizaje de la lengua como un relato culturalmente inseparable, y su puesta en crisis en la reescritura de los poemarios que aquí se abordan como la posibilidad de rebelarse contra ese sistema paternalista.

La imagen maternal, por su parte, sí está presente en los poemas de Ortega como mujeres que observan los juegos eróticos de los niños, en una situación contradictoria de rechazo y deseo: "nuestras madres comentan lo que hacemos pero no lo llaman cariño, lo dicen arrugando la cara, moviendo la lengua, haciendo arcadas, revolcándose en el comedor, 
las he visto vomitando, en el baño, sobre las cortinas, las he descubierto imitándonos" (s/r). En este poema, sin título, aparece un fragmento escaneado del Silabario Hispanoamericano con la oración "besé a mi mamá" (s/r). La relación erótica que aquí se enuncia es una respuesta a la orfandad del sujeto infantil, o bien, una relación de dos sujetos expuestos a la violencia de ser los huachos, los otros, los bárbaros, como lo presenta el poema "Colmillo de leche" que acompaña a la imagen que presentamos más arriba. En este poema, escrito en prosa, el hijo recuerda la caída de sus dientes de leche, en un relato donde madre e hijo conviven entre el amor maternal y la violencia; “¿cuántos dientes me sacaste y cuánta leche me hiciste tomar para tenerlos más lindos?”, pregunta el niño a la madre para sostener, luego, en un tono macabro: "el sonido del alicate rechinado en mi boca, mientras me sacabas los dientes, me ponía frágil" (s/r). Tras esta violencia filial, madre e hijo buscan ser escuchados, pero también buscan salir de la marginalidad, como sugiere el final del poema: “quizás alguien nos escuche y nos devuelva los dientes, sería más fácil masticar, podríamos sonreír y así los niños en el colegio no se reirían de nosotros" (s/r). Esos dientes perdidos que no tienen origen, cuerpo, identidad; funcionan como metáfora de estos sujetos otros, apartados y arrancados a la fuerza de la cultura y la historia.

En relación con lo anterior, podemos ver que la educación primaria también expone esta relación de despojo entre niños y mujeres como sujetos "menores" en la sociedad republicana. Al respecto, la poeta uruguaya Juana de Ibarbourou deja constancia de la feminización de la educación básica en la dedicatoria que aparece en el Silabario Hispanoamericano: “AAh!, ¡cuánto tienen que agradecerle madres y maestras a ese hermoso talento creador, a ese puro corazón intuitivo que ha hecho para los niños de las Américas este libro perfecto!" (5). Con estas palabras cobra sentido que las primeras escuelas gestionadas por el gobierno de Chile y pensadas para este grupo de niños empobrecidos estuvieran dirigidas por mujeres en las mismas condiciones de precariedad, siendo posible su existencia gracias a ellas (cf. Salazar y Pinto), y no tanto por los pocos aportes estatales, que además significaban estar bajo la supervisión de autoridades que presionaban y abusaban de estas maestras, situación que llevó a pensar que la educación primaria era un espacio de inmoralidad, como argumentan los historiadores chilenos.

Volviendo al poema de Ortega, niño y mujer logran reencontrarse en esta relación "salibárica", donde la saliva, a la que hace referencia el 
título, propone un erotismo salvaje, pero también un espacio anterior a la sílaba, un balbuceo primitivo que nos remite a la rabia como patología. Es en ese territorio donde la palabra quiere ser conquistadora. Y es en este sentido que Salibario reescribe la infancia para volver a leer la niñez. El poema aborda de forma crítica la violencia institucional ejercida contra los niños y niñas de Chile para explorar desde allí su propia historia y producción en tanto constructo político e ideológico de lo que significa ser (o llegar a ser) ciudadano.

El uso del Silabario Hispanoamericano permite reconocer este fenómeno en el trabajo de Dufflocq, quien cubre la violencia a través de la enseñanza de valores morales y patrióticos con historias e ilustraciones fantásticas que, en el caso de Ortega, vuelven dislocadas para tensionar la perspectiva ingenua e infantilizada del niño y la infancia. Su poema articula nuevos significados del sujeto infantil en las imágenes de Coré, a partir de los textos que acompañan la ilustración ${ }^{11}$, en una actualización del texto pedagógico que invita a revisar el presente histórico de la niñez en relación con esta tradición de la violencia patriarcal del Estado como ente regulador de la vida de aquellos sujetos que son considerados "menores" frente al hombre político y republicano.

\section{La reescritura como juego, el juego como liberación}

"Niños de este mundo o del otro"

Los silabarios no solo funcionan como método de aprendizaje de la lengua, también enseñan reglas y normas de conducta que se expresan en valores (morales, éticos, patrios, etc.), sobre todo a partir de las lecturas complementarias. Como advertimos en Salibario de Rodrigo Ortega, estas normas son civilizadoras en la medida en que son administradas por medio del aprendizaje de la lengua. En Silabario, Mancha, la poeta Marcela Parra $^{12}$ desencaja la normatividad del Silabario Hispanoamericano, acer-

\footnotetext{
11 En su ensayo Arte del coleccionismo, Benjamin nos dice que es en el abecedario ilustrado y el diccionario visual donde encontramos los inicios del libro infantil, cuya relación entre imagen y palabra se remonta a los grabados de las maravillas del mundo del siglo XVII o incluso antes (41). Es en esta tradición, entonces, que debemos pensar la asociación entre Dufflocq y Coré, que es decir, a la vez, la asociación entre palabra e imagen.

12 Marcela Parra (1981): poeta, cantante, compositora y artista visual. Es licenciada en Artes Visuales de la Universidad de Playa Ancha. Entre sus publicaciones se encuentran Silabario, Mancha (anticipio)
} 
cándolo al juego con el lenguaje de la tradición vanguardista y, específicamente, con La Nueva Novela de Juan Luis Martínez (1985) que se mantiene presente a lo largo de todo el texto.

Podemos corroborar la cercanía entre el poemario de Parra y el silabario de Dufflocq desde el título hasta la reescritura de algunos fragmentos que se presentan en el poema "Silabario para los maestros" (22), que tiene como protagonista a Perico ${ }^{13}$, un estudiante que se encuentra en el proceso de aprendizaje de la lengua: "La lengua de Perico en el pizarrón / de forma consecuente dijo la lección” (22). Los errores de Perico generan la risa de los estudiantes y el enfado del maestro. El poema continúa entre lecciones lingüísticas a través de ejercicios tomados del Silabario Hispanoamericano, recortadas en verso y propuestas para el juego del poema y no para su resolución, como se observa en los siguientes versos: "La isla está lejos / La noche está oscura / Las focas son feas / La araña es peluda” (22).

El juego de Perico también es una cita a La Nueva Novela, por cuanto los amigos del estudiante "lo quieren alegrar / con sus figuras del mundo animal" (23), verso que remite a "La zoología” de Juan Luis Martínez en la quinta sección de dicho libro, descrito como un "bestiario en extremo singular: sus animales nos enfrentan a situaciones que, como compete a la tradición, están cerca del horror, pero de un horror lúdico que surge del extrañamiento que producen los juegos paradojales a que los somete y nos somete" (Galindo 22); y de donde hemos tomado el epígrafe de esta sección: "Niños de este mundo o del otro: / sabed que a orillas del Alfabestiario Universal de Dios / como a orillas de un lago, (y no está demás decirlo), / merodea entre otros animales imaginarios y reales: / EL ANIMALFABETO" (Martínez 73). Los versos de Parra permiten observar una paradoja entre violencia y fantasía, cuando Perico burla la normatividad de la escuela, como institución formativa de la lengua, para jugar con ella.

(2007), Silbario, Mancha (2008), Ambulancia (2010), además de contar con varios poemas publicados en antologías chilenas y extranjeras.

13 Perico representa la imagen del niño escolar. En el libro Qué será de los niños que fuimos (2017), Claudio Guerrero realiza una tipología de la niñez en la escritura poética chilena. Sin embargo, el niño escolar como tipo no aparece en su listado, a pesar de que sí construye una lectura crítica en relación a lo pedagógico, como sucede en la lectura de Poema de Chile de Gabriela Mistral, donde considera la relación didáctica de la "mama" con el niño. Al respecto, es interesante evidenciar la ausencia de la escuela en favor de una pedagogía no institucionalizada, rescatando la mirada subalterna en torno a lo educativo. 
Por otro lado, en la página 27 del Silabario Hispanoamericano Coré ilustra una jaula llena de aves ${ }^{14}$. El lector debe responder varias preguntas a partir de esta ilustración. Y son estas las preguntas que utiliza Marcela Parra para continuar con el poema: “¿Cuántos son todos? / ¿Cuántos vuelan? / ¿Cuántos en la rama? / ¿Cuántos comiendo? / ¿Cuántos fuera de la jaula? / ¿Cuántos dentro de la jaula?” (24). En su disposición en verso, las preguntas generan nuevas significaciones del ejercicio didáctico. Una posibilidad es pensar que este personaje, en tanto sujeto escolar/escolarizado, se identifica con estas aves sujetas a un afuera o a un adentro de la lengua o de la escuela. Además, antes del fragmento citado, la poeta da espacio a la confusión entre los planos de realidad y fantasía cuando señala que "Perico mira una pajarera / mientras se saca las lagañas" (24). El personaje puede estar frente a una pajarera en el colegio o frente a la lámina de Coré. Este gesto permite cuestionar la posibilidad de la lengua como medio de representación de lo real, anteponiéndose al método fónico-sensorial de Dufflocq, donde imagen y palabra se corresponden para dar cuenta de una realidad objetiva. Sobre esto, el poema “Trompel'oeil (o silabario de la mancha)" nos permite comprender esta propuesta.

El Trompel'oeil, o trampantojo en su traducción del francés, es definida por la R.A.E. como una trampa o ilusión con que se engaña a alguien haciéndole ver lo que no es. Bajo esta perspectiva, Parra propone un silabario desde la mancha, donde el aprendizaje de la lengua se entiende como ilusión o efecto visual. Así, en los primeros versos del poema, leemos: "La mancha está en el ojo / su nombre anterior es mixtura" (12), lo cual indica que la lengua es una mancha que, antes de ser interpretada por nuestros sentidos, es intercambio y mixtura, una mezcla indiferenciada, contraria a las imágenes de Coré, donde cada ilustración encajaría en un orden establecido por la palabra, en una

\footnotetext{
14 Destacamos esta imagen, reescrita en el poema de Marcela Parra, sobre todo por el cruce con la ilustración de la página 88 de La Nueva Novela, donde vemos un grupo de pájaros con varios pentagramas que recuerdan las celdas de las jaulas. Este cruce nos lleva a la nota al pie de página que acompaña al poema "Observaciones relacionadas con la exuberante actividad de la 'confabulación fonética' o 'lenguaje de los pájaros' en las obras de J. P. Brisset, R. Roussel, M. Duchamp y otros”, donde Martínez dice que: "(el español es una lengua opaca, / con un gran número de palabras fantasmas; / el pajarístico es una lengua transparente y sin palabra)” (89), contraponiéndose a las palabras de Dufflocq: “creo que el idioma castellano es el más fácil del mundo para aprender a leerlo y escribirlo como lengua materna, pues le falta un soplo para llegar con precisión a esa inmutabilidad de las matemáticas, vale decir, de la ciencia más que exacta que ha ideado el hombre hasta nuestros días" (s/r).
} 
relación de significante y significado, pues, alfabetizar es entender la palabra como interpretación de un mundo real y objetivo.

En el poema "Silabario para maestros", encontramos esta relación enseñada a través de la educación primaria. Es la lengua de Perico, "moviéndose al compás / de vocales, consonantes / que dan forma a su pensar" (23), la que es cuestionada desde la rebeldía del personaje: "Perico decide escapar de la escuela / imaginando una gran lista / de cosas afuera" (23). Esta larga lista de "cosas" que se hallan fuera de la escuela se compone de frases del Silabario Hispanoamericano (33) que pierden sentido en este nuevo escenario (el afuera del espacio escolar) cuando evidencian una suerte de deriva en que las oraciones utilizadas en el aprendizaje de la lengua ya no significan nada, puesto que han perdido su contexto original, al tiempo que han ganado otros sentidos en la posibilidad poética de significar más allá del contenido semánticogramatical de las oraciones.

Por otra parte, y retomando la relación con La Nueva Novela, en Silabario, Mancha se observa una continuidad con la obra de Juan Luis Martínez desde la combinatoria como un juego poético o, como diría Elvira Hernández, de la poesía como juego. En esta línea, es ejemplificador el poema "Se busca objeto perdido", en que Parra utiliza la imagen de una tarjeta del juego de mesa Gran Santiago, incluyendo dos versos que resignifican el objeto ilustrado. La poeta permite entender, en este caso, el Silabario Hispanoamericano desde la poesía visual ${ }^{15}$ que Enrique Lihn anunció en el trabajo de Coré al indicar que el ilustrador fue un "poeta visual" (S/R) que no perteneció únicamente a una tradición infantil.

El ámbito pedagógico que sustenta el silabario se ve excedido, en estos ejercicios poéticos, por la educación visual sugerida mediante las ilustraciones de Coré, que no solo decoran las palabras con sus láminas coloridas, sino que también abren la posibilidad de resignificar la palabra y encontrar una nueva forma de entender la lengua. De este modo, la

15 Para Dennis Páez (2012), la poesía visual consiste en "un tipo de poesía que se deja ver, para lo cual ha ido posicionándose en terrenos distintos, instalándose en espacios públicos, valiéndose de recursos que se encuentran en situaciones cotidianas, aproximando la experiencia estética a la vida diaria de las personas" (46). Debemos agregar que la poesía visual en Latinoamérica tiene sus precedentes en las primeras décadas del siglo xx con Vicente Huidobro y Oliverio Girondo, y la poesía concreta en Brasil como el gran hito a nivel continental en lo que a esta línea poética se refiere. 
reescritura del Silabario Hispanoamericano posibilita una lectura que sobrepasa la interpretación normalista.

La relación entre el trabajo de Dufflocq y Coré, en tanto poesía visual, produce en el signo poético una relación tensionada entre imagen y palabra, que la presencia material y simbólica de La Nueva Novela lleva a su fin en el momento de la lectura. De esta manera, en la tensión que provoca Marcela Parra entre el Silabario Hispanoamericano y La Nueva Novela, debemos mencionar y recalcar las posibilidades de encuentro entre signos de naturaleza diferente para una nueva lectura de La Nueva Novela, desde el cruce con el libro educativo (sobre todo, con aquellos que tienen un enfoque de alfabetización). En el caso de Martínez, el aprendizaje apunta a desarmar esa alfabetización, desarmar aquello que sabemos sobre la lengua. Un ejemplo de esta posibilidad está en el poema "Meditaciones sobre René Magritte" (93), donde encontramos un juego en la separación silábica de la palabra "pipa", acompañada de una imagen del mismo objeto partido por la mitad. Asimismo, también es una pipa la que da comienzo a los ejercicios de Dufflocq en la página número 8 del Silabario, donde la palabra "pipa" es acompañada por una ilustración del mismo objeto.

Los antagonismos asociados entre una obra y otra posibilitan, finalmente, la relectura del texto educativo, donde el cruce es llevado a cabo sobre todo por el juego. En el caso de Dufflocq, el juego es mediado por la instrucción republicana de la lengua y, en el caso de Martínez, es un juego que busca reescribir para desaprender la normatividad de los códigos de la lengua y la cultura. El encuentro de ambos jugadores recuerda las siguientes palabras de Benjamin: “así como el mundo perceptivo del niño se encuentra atravesado en todas partes por huellas de las generaciones más antiguas y en confrontación con ellas, lo mismo ocurre con sus juegos" (54). El juego es el espacio donde la tradición es aprendida y transformada a fuerza de repetición, "la gran ley que rige el mundo de los juegos" (58); pues, si la reescritura es entendida como un juego a partir de la repetición, debemos agregar que jugar supone un acto de liberación. 


\section{Palabra ausente}

"Tarea de la infancia: traer el nuevo mundo al espacio simbólico"

Walter Benjamin

En el ensayo "La redefinición del contrato simbólico entre escritor y lector: La Nueva Novela de Juan Luis Martínez", la poeta Eugenia Brito propone a Martínez como inaugurador de la nueva escena literaria chilena, argumentando que es el tema del nombre «indescible» el que es introducido por La Nueva Novela en dos sentidos:

El primero de ellos, como el quiebre con el significado trascendental propio del logos mantenido por el sistema cultural a través de la figura (tachada) del padre y de la familia (círculo) regida por él. El segundo de ellos como una incomodidad radical sostenida por el libro y por el que escribe con respecto a ese lenguaje y esa cultura; a las que estratifica, significante tras significante, intentando en esa, por un lado fuga, por otra, excavación, atravesar esas operaciones a la búsqueda del silencioso lenguaje materno. (Hernández y Fariña 16)

En esta perspectiva, la relación polémica entre la poesía de los 90 frente a la de los 2000, sugerida por algunas lecturas, como las de Héctor Hernández o Tomás Harris ${ }^{16}$, se ve alterada al reconocer un encuentro en el autor porteño, donde reescritura y poesía visual comparten espacio como continuadores de esa búsqueda por negar y desarmar el sistema cultural hegemónico que recae sobre la institución social de la lengua.

La respuesta cultural ante ese padre ausente o presente desde la violencia patriótica hace resurgir la idea de la mujer como imagen de una cultura por descubrir. Lo que Brito llama "el silencioso lenguaje materno" (16). Este lenguaje materno es el que encontramos en Bracea de Malú Urriola $^{17}$, en la madre que "deja de padecer la historia para escribirla"

\footnotetext{
16 Sobre la poesía chilena a comienzos del siglo xxi, Maximino Fernández (2007) presenta las opiniones divergentes suscitadas ante el surgimiento de la novísima, sobre todo desde la publicación de la antología Cantares. Nuevas Voces de la Poesía Chilena (2004), a cargo del poeta Raúl Zurita. La polémica se sustenta en la diferenciación de una escena académica de los noventas, con los llamados "náufragos" (Andrés Andwanter, Jaime Huenún, Alejandra del Río, etc.), frente a otra de carácter popular o contracultural en los dos mil, con la novísima (Héctor Hernández, Paula Ilabaca, Diego Ramírez, Felipe Ruiz, etc.).

17 Malú Urriola (1967), poeta y guionista chilena de amplia trayectoria. Obtuvo el Premio Pablo Neruda por unanimidad el año 2006, logrando situarse como una de las poetas más importantes del país. Entre sus libros de poesía destacan: Piedras Rodantes (1988), Hija de perra (1998), Las estrellas de Chile para
} 
(107). El encuentro de las mujeres a través de la escritura que aparece en el poemario de Urriola permite retroceder a la historia de la educación primaria que mencionamos anteriormente, cuyo origen encontramos en las escuelas filantrópicas que, como dice Salazar, funcionaron no tanto por la gestión estatal como por el trabajo del "peonaje femenino que las regentaba" (58).

En Bracea, también aparece la ausencia del padre a través de las hermanas siamesas que guían este relato y de Tres Piernas, otro personaje deforme que participa en esta historia, donde lo monstruoso de esa marginalidad está dado por la palabra del patriarca: "mi hermana me dijo que nuestro padre nos odia porque somos monstruosas" (41). La misma monstruosidad que aleja al padre de Tres Piernas: "el padre de Tres Piernas no se despidió de nadie. / De pronto un día ya no estuvo. / Dicen en el pueblo que se fue montaña adentro" (98). Los poemas de Bracea se unen a la opinión histórica de Salazar sobre el rol de los padres, cuando este afirma que: "a la ausencia del padre ("que caminaba la tierra") se unía la compulsión de la madre (por su "mucha miseria") en la acción de botar, vender, regalar y deshacerse de la prole" (53), una prole cuya historia se piensa desde la identidad ruinosa que trae consigo el castigo de la pobreza y la marginalidad. Pero, así como la historia ha sobrepasado el relato de los vencedores para traer al presente el relato histórico de la niñez, la mujer ha logrado aparecer aquí y ahora con el fin de escribir su propia historia.

Así como Ortega tachaba la palabra para evidenciar la ausencia, Urriola utiliza la imagen con la misma finalidad, tal como sucede en un poema sin título de Bracea, donde una de las hermanas relata que el padre tomó la bicicleta de sus hijas para irse, regresando a casa sin esta. La poeta utiliza un dibujo que recuerda a los ejercicios utilizados en la enseñanza de la lectura, donde las imágenes sustituyen a las palabras en las oraciones:

Entonces mi padre nos quitó la bicicleta y la usó para irse. Una madrugada llegó borracho y con la bicicleta destruida. Dijo - tratando de evitar el hipo-que un automóvil lo arrolló en la carretera.

Él — gracias a dios - logró salvarse, pero nuestra alemana, no. (39) 
Esta cita, al uso de la imagen en la alfabetización de los niños, enfatiza que la pedagogía no solo tejió sus redes en el aprendizaje de la palabra escrita, sino también que, en su revés, está la educación visual; un problema pedagógico que, de acuerdo con Benjamin, abarca lo cultural en el lema “ipor el signo en contra de la palabra!" (42). En este "contra la palabra", la poesía visual se presenta como una herramienta a favor del desarme cultural que aparece de forma explícita en La Nueva Novela. El juego poético es revolucionario porque el juego, dice Benjamin (2017), se encuentra atravesado por las generaciones más antiguas y en confrontación con ellas; de ahí también la importancia de la reescritura entre textos verbales y visuales, pedagógicos y literarios, como recurso que promueve el cruce intencional con la tradición.

En Bracea de Malú Urriola, la lámina de la página 99 en que aparece la portada del Silabario Hispanoamericano, pasa desapercibida por ser el único lugar donde se menciona el texto de Dufflocq de manera evidente. Sin embargo, el poemario refleja la intención que hemos venido sugiriendo, donde la reescritura funciona a favor del desarme de la lengua aprendida, que es, a la vez, el desarme de nuestra cultura patriarcal donde el hombre blanco, letrado y heterosexual es el sujeto-ciudadano por supremacía. Este desarme aparece representado en los siguientes versos, donde la palabra "papá” es separada en sílabas:

Mi hermana escribe pi-pa, pe-pe, pa-pá y -como decía nuestro padre que ella era la que tenía el corazón- sufre su falta en silencio.

Lo que extraña mi hermana es pronunciar la palabra padre.

Yo extraño las palabras que no conozco. (101)

La hermana, que no tiene el corazón, extraña la palabra que no conoce, la no aprendida o la anterior al lenguaje. Como se insinúa en el poema sin título, que se sitúa frente a la portada del silabario, esta mujer, niña y madre a la vez, aprendió a escribir antes de la enseñanza de la escritura. Y en ese antes de la enseñanza está la palabra no conocida, un antes donde la cultura del hombre no es ley.

La palabra faltante es también metáfora de los sujetos desconocidos por la historia oficial, como la mujer y el niño en la historia reciente de Chile. Es en la imagen visual que los sentidos se dejan llevar por una vía alternativa, donde las ilustraciones de Coré van sedimentando no solo nostalgias de un pasado irrecuperable, sino también la actualización de 
ese pasado a través de estos discursos negados por el relato oficial de la Historia. Así, desde el ejercicio del "braceo" se construye la posibilidad de resignificar la palabra, tanto como las identidades de estos sujetos: "sería la palanca que impulsa, desde lo que está, un nuevo horizonte de representación" (Rojas 42), el juego como ejercicio de aprendizaje y, a la vez, transformación de la tradición.

La reescritura del silabario es una propuesta donde este juego con la tradición no solo se evidencia, sino que además se problematiza. Tras él está la necesidad de cuestionar el carácter normativo que se ha ejercido en la lengua y a través de ella en el sujeto infantil. Tal vez las palabras, "vehemente puedan librarse y salir braceando", como dice Urriola, en un poema sin título, "como un centenar de mariposas de colores, negras y azules, dispersándose en el aire, liberadas de esta jaula infame” (56). Estos versos expresan la finalidad de volver a citar los orígenes de su propia palabra en tanto producto cultural aprendido por medios pedagógicos.

\section{Desaprender la lengua}

Así como el proyecto de Dufflocq buscaba dar una respuesta pedagógica a las altas tasas de analfabetismo que vivía nuestro país en la primera mitad del siglo xx, el regreso de este proyecto a través de la poesía nos permite dar con el ejercicio contrario: el de desaprender la lengua y regresar al analfabetismo primario para comenzar nuevamente, en un juego de repeticiones diferidas, en un "otra vez", como sugiere Benjamin, capaces de subvertir los significados hegemónicos de la cultura patriarcal.

La reescritura del Silabario Hispanoamericano en Rodrigo Ortega presenta la actualidad del niño huacho y la violencia sociocultural en la convivencia entre este y la mujer a través del abandono, haciendo visible la manera en que la educación ha forjado la unión entre estos dos sujetos, sobrepasando el marco educativo de la formación moral que se escondía en los procesos de alfabetización. Por otro lado, este marco educativo, que sobrepasa las expectativas del Estado, da como resultado una tradición otra, donde se fue gestando la posibilidad de usar la palabra no desde la norma, sino desde la contranorma, del desarme, del desajuste respecto a ella, como plantean los poemas de Marcela Parra, quien articula la imagen del niño que logra salir del aula para burlar la normatividad de la enseñanza de la lengua y jugar con ella, regresando a un antes de la letra, a la mixtura, a la mancha o a la imagen visual que funciona como una 
reescritura lúdica de la lengua (que es el origen); legado que, en manos del dibujante Coré, fue abriendo una grieta por donde tendría cabida la poesía visual en su carácter contestatario. Por último, Malú Urriola nos presenta un panorama acabado de estas problemáticas, desde la relación maternal que une a mujeres y niños a través de la palabra, pero no desde la educación de la palabra como simple acto de alfabetización, sino desde la posibilidad que tienen los sujetos marginados por las instituciones del Estado nacional de hacerse presentes en esa palabra, de manera de poder desarmar los significados establecidos y así liberar la palabra.

La poesía chilena reciente, abocada a problematizar las figuras culturales del niño y la infancia, permite leer el Silabario Hispanoamericano al revés, como si pudiésemos retornar también a nuestra infancia (histórica y personal) para encontrar ese momento de cruce con la palabra/imagen e ir incluso antes, al lugar del analfabeto, el iletrado, que, en palabras de Agamben (2015), es el verdadero destinatario de la poesía.

\section{Referencias bibliográficas}

Agamben, Giorgio. “¿A quién se dirige la poesía?”. New Observations. Trad. Daniel Heller-Roazen, no. 130, 2015.

Apablaza, Claudia. "La poesía es un llamado de alerta. Conversaciones con Héctor Hernández Montecinos”, 2009. Recuperado de: http://letras.mysite.com/ hh120609.html

Benjamin, Walter. La tarea del crítico. Santiago de Chile, Hueders, 2017.

Dufflocq, Adrián. Silabario Hispanoamericano. Santiago de Chile, Stanley, 1953.

Fernández, Maximino. Historia de la Literatura Chilena. Tomo II. Santiago de Chile, Don Bosco, 2007.

Galindo, Oscar. "El alfabestiario universal de La Nueva Novela de Juan Luis Martínez". Revista chilena de literatura, no. 57, 2000, pp. 21-40.

Guerrero, Claudio. Qué será de los niños que fuimos. Imaginarios de infancia en la poesía chilena. Valparaíso, Ediciones Inubicalistas, 2017.

Hernández, Biviana. “Aproximaciones a la infancia desde la poesía chilena del siglo XXI". Literatura y Lingüística, no. 37, 2018, pp. 115-136. 
Hernández, Biviana y Francisco, Simon. "La mala leche que las parió. Ciudadanías neoliberales en la poesía chilena del siglo XXI". Revista Chilena de Literatura, no. 96, 2017, pp. 209-234.

Hernández, Elvira y Soledad Fariña. Merodeo en torno a la obra poética de Juan Luis Martínez. Santiago de Chile, Interperie, 2001.

Lihn, Enrique. El retorno de Coré. Providencia, Galería Visuala, 1985.

Lihn, Enrique y Pedro Lastra. Señales de ruta de Juan Luis Martínez. Santiago de Chile, Archivo, 1987.

Martínez, Juan Luis. La Nueva Novela. Santiago de Chile, Ediciones Archivo, 1985.

Matte, Claudio. Nuevo método (fonético, analítico-sintético) para la enseñanza simultánea de la lectura i escritura compuesto para las escuelas de la República de Chile. Leipzig, Impr. de F.A. Brockhaus, 1884.

Oltra, Sandra y Ana María Puga. "Psicopatologización de niños y jóvenes en las instituciones públicas". Infancias, familias y estado. Comp. Paulina Fernández et. al. Santiago, Ediciones UCSH, 2015, pp. 65-75.

Orrego Luco, Augusto. "Hombres, ideas y hechos. El movimiento literario de 1842". Atenea: revista mensual de ciencias, letras y artes, no. 203, 1924, pp. 317-350.

Ortega, Rodrigo. Salibario. Santiago de Chile, Moda \& Pueblo, 2012.

Páez, Dennis. "Poesía visual en Chile. Una cartografía de las prácticas visuales en la poesía chilena”. Repositorio Conicyt, 2012. Recuperado de: http://repositorio.conicyt.cl/ bitstream/ handle/10533/181711/PAEZ DENNIS 2394M.pdf?sequence=1

Parra, Clara. "Fuentes y herramientas para el estudio para la formación del niño lector en Chile (1860-1960)". Ocnos: Revista de Estudios sobre Lectura, vol. 16, no. 1, 2017, pp. 144-155.

Parra, Marcela. Silabario, Mancha. Santiago de Chile, Ediciones del Temple, 2008.

Real Academia Española. “Diccionario de la lengua española; edición del tricentenario", 2017. Recuperado de: http://dle.rae. es/?id=aGlyc8T 
Rojas, Gonzalo. "Fugacidades e inanidades en Nada y Bracea de Malú Urriola”. Catedral Tomada: Revista de Crítica Literaria latinoamericana, no. 8, 2017, pp. 33-46.

Salazar, Criss. "El Silabario Hispano Americano del profesor Dufflocq y los buenos días de la educación chilena". Urbatorium.blogspot. com. 2011. Recuperado de: https://urbatorium.blogspot.com/ 2011/09/el-silabario-hispano-americano-del.html

Salazar, Gabriel y Julio Pinto. Historia contemporánea de Chile V: niñez y juventud. Santiago de Chile, Lom ediciones, 2002.

Sarmiento, Domingo Faustino. Análisis de las cartillas, silabarios y otros métodos de lectura conocidos y practicados en Chile. Santiago de Chile, Imprenta del progreso, 1842.

. Método de lectura gradual. Santiago de Chile, Imprenta de Julio Belin i Ca., 1849.

Subercaseaux, Bernardo. Historia de las ideas y de la cultura en Chile; nacionalismo y cultura. Santiago de Chile, Editorial Universitaria, 2007.

Urriola, Malú. Bracea. Santiago de Chile: Lom Ediciones, 2007. 